\title{
Ventilatory drive and the apnea-hypopnea index in six-to-twelve year old children
}

\author{
Ralph F Fregosi*1, Stuart F Quan ${ }^{2,5}$, Andrew C Jackson ${ }^{6}$, Kris L Kaemingk ${ }^{3,4}$, \\ Wayne J Morgan ${ }^{2,4}$, Jamie L Goodwin ${ }^{2,5}$, Jenny C Reeder ${ }^{1}$, Rosaria K Cabrera ${ }^{1}$ \\ and Elena Antonio ${ }^{1}$
}

\begin{abstract}
Address: ${ }^{1}$ Department of Physiology, The University of Arizona, Tucson, USA, ${ }^{2}$ Arizona Respiratory Center, The University of Arizona, Tucson USA, ${ }^{3}$ Steele Memorial Children's Research Center, The University of Arizona, Tucson, USA, ${ }^{4}$ Department of Pediatrics, The University of Arizona, Tucson, USA, ${ }^{5}$ Department of Medicine, The University of Arizona, Tucson, USA and ${ }^{6}$ Department of Biomedical Engineering, Boston University, Boston, USA

Email: Ralph F Fregosi* - Fregosi@u.arizona.edu; Stuart F Quan - squan@resp-sci.arizona.edu; Andrew C Jackson - ajax@bu.edu; Kris L Kaemingk - kaemingk@peds.arizona.edu; Wayne J Morgan - wmorgan@ resp-sci.arizona.edu; Jamie L Goodwin - jamieg@respsci.arizona.edu; Jenny C Reeder - reederjc@yahoo.com; Rosaria K Cabrera - rmkelley@email.arizona.edu;

Elena Antonio - eantonio@u.arizona.edu

* Corresponding author
\end{abstract}

Published: 29 April 2004

BMC Pulmonary Medicine 2004, 4:4

This article is available from: http://www.biomedcentral.com/I47/-2466/4/4

(c) 2004 Fregosi et al; licensee BioMed Central Ltd. This is an Open Access article: verbatim copying and redistribution of this article are permitted in all media for any purpose, provided this notice is preserved along with the article's original URL.

\begin{abstract}
Background: We tested the hypothesis that ventilatory drive in hypoxia and hypercapnia is inversely correlated with the number of hypopneas and obstructive apneas per hour of sleep (obstructive apnea hypopnea index, OAHI) in children.
\end{abstract}

Methods: Fifty children, 6 to 12 years of age were studied. Participants had an in-home unattended polysomnogram to compute the OAHI. We subsequently estimated ventilatory drive in normoxia, at two levels of isocapnic hypoxia, and at three levels of hyperoxic hypercapnia in each subject. Experiments were done during wakefulness, and the mouth occlusion pressure measured 0.1 seconds after inspiratory onset $\left(\mathrm{P}_{0.1}\right)$ was measured in all conditions. The slope of the relation between $\mathrm{P}_{0.1}$ and the partial pressure of end-tidal $\mathrm{O}_{2}$ or $\mathrm{CO}_{2}\left(\mathrm{P}_{\mathrm{ET}} \mathrm{O}_{2}\right.$ and $\left.\mathrm{PET}_{\mathrm{ET}} \mathrm{CO}_{2}\right)$ served as the index of hypoxic or hypercapnic ventilatory drive.

Results: Hypoxic ventilatory drive correlated inversely with OAHI $(r=-0.3 \mathrm{I}, \mathrm{P}=0.04 \mathrm{I})$, but the hypercapnic ventilatory drive did not $(r=-0.19, P=0.27)$. We also found that the resting $\mathrm{P}_{\mathrm{ET}} \mathrm{CO}_{2}$ was significantly and positively correlated with the $\mathrm{OAHI}$, suggesting that high $\mathrm{OAHI}$ values were associated with resting $\mathrm{CO}_{2}$ retention.

Conclusions: In awake children the OAHI correlates inversely with the hypoxic ventilatory drive and positively with the resting $\mathrm{P}_{\mathrm{ET}} \mathrm{CO}_{2}$. Whether or not diminished hypoxic drive or resting $\mathrm{CO}_{2}$ retention while awake can explain the severity of sleep-disordered breathing in this population is uncertain, but a reduced hypoxic ventilatory drive and resting $\mathrm{CO}_{2}$ retention are associated with sleep-disordered breathing in 6-12 year old children. 


\section{Background}

Sleep-disordered breathing occurs in children as well as adults, with many investigators assuming that the primary cause is an anatomic abnormality of the pharyngeal airway [1]. However, studies in adults suggest that altered ventilatory control may play a role in the pathogenesis of sleep-disordered breathing [2,3]. It remains unclear, however, whether this is also true in children. Marcus et al [4] showed that, compared to control subjects, children with sleep-disordered breathing had diminished arousal responses when challenged with hypercapnia during sleep. However, the children with sleep-disordered breathing had normal ventilatory responses to hypercapnia and hypoxia. The authors concluded that although hypercapnia-induced arousal was abnormal in the children with sleep-disordered breathing, the response of the ventilatory control system to hypoxia and hypercapnia appeared normal. In another recent study [5], the hypercapnic and hypoxic ventilatory responses in awake children with sleep-disordered breathing were similar to those measured in control subjects matched for age and body mass index, providing more evidence that the control of breathing is relatively normal in children with sleep-disordered breathing.

The present study was designed to extend previous work in two ways. First, the study of Marcus et al. [5] used a cross sectional design (a group of control subjects compared to a group of subjects with sleep disordered breathing) so it is not clear whether or not the hypoxic or hypercapnic ventilatory drive correlates with the severity of sleep-disordered breathing. Here we examine the correlation between the severity of sleep-disordered breathing (defined as the obstructive apnea hypopnea index, OAHI) and ventilatory drive. Ventilatory drive was estimated by measuring the mouth occlusion pressure response $\left(\mathrm{P}_{0.1}\right)$ to isocapnic hypoxia and hyperoxic hypercapnia with linear regression analyses. Our use of the $P_{0.1}$ rather than the change in pulmonary ventilation is, in our view, an important feature of the experiments. The ventilatory response in children can be difficult to interpret because the large differences in size among children separated by even a few years in age make their ventilatory responses to chemoreceptor stimulation highly variable. Although Marcus et al [5] corrected their subject's ventilatory responses for body surface area, the coefficient of variation of the corrected ventilatory response to hypoxia was still 50\%. Similarly, Honda et al. [6] reported that coefficient of variation values for body surface area-corrected hypoxic ventilatory responses ranged from $63-81 \%$ in children aged 7-12 years (see their Table 1). These data suggest strongly that body surface area may not adequately correct the ventilatory response for body size in young children. In contrast, the $\mathrm{P}_{0.1}$ technique, wherein inspiratory flow is completely occluded for a brief period
[7] is similar in adults and children (compare values in Marcus et al. [8] with values reported by Whitelaw et al. [7] and also with the present data), and therefore does not need to be scaled for size. This is consistent with the measurement of other pressures in mammals, which also do not vary with body size (e.g., blood pressure, [9]). Thus, using $\mathrm{P}_{0.1}$ as an estimate of ventilatory drive in children extends previous work as this index is less influenced by large differences in body size across the subject population.

Resting $\mathrm{CO}_{2}$ retention suggests a reduced hypercapnic ventilatory drive [10-13], and has been associated with sleep disordered breathing in children $[14,15]$ and adults [2]. Adeno-tonsillectomy has been shown to normalize the $\mathrm{CO}_{2}$ retention in some studies [16], but not others [15]. Accordingly, we also measured the partial pressure of end-tidal $\mathrm{CO}_{2}\left(\mathrm{P}_{\mathrm{ET}} \mathrm{CO}_{2}\right)$ during quiet wakefulness in all subjects, and used linear regression analysis to test the hypothesis that children with higher OAHI values retain $\mathrm{CO}_{2}$.

\section{Methods Subjects}

All methods used to recruit subjects and to collect the present data set were approved both by the University of Arizona Human Subjects Committee and the Tucson Unified School District Research Committee. In all cases, we obtained written informed consent from the parents, and assent from the children. Subjects were recruited through the Tucson Unified School District (TUSD), a very large district with an elementary school population representative of children living in Southern Arizona. Typically, all parents at 8 elementary schools were asked to complete a short, anonymous, sleep habits screening questionnaire and to indicate if they would allow study personnel to call and schedule a polysomnogram for their child. The overall response rate was $31.6 \%$. The screening questionnaire consists of a one-page, 13-item survey designed to assess the severity of sleep-disordered breathing related symptoms in children. Questions such as: "How often does your child snore loudly?"; "Is your child sleepy during the daytime?"; and "Does your child stop breathing during sleep?", were evaluated by the parent on the scale of 'Never', 'Rarely', 'Occasionally', 'Frequently', 'Almost Always' or 'Don't Know'. Additional questions were asked on the night of the polysomnogram with a more extensive sleep habits questionnaire. Composite variables were created based on a combination of selected survey items. Habitual snoring, daytime sleepiness, and/or insomnia were reported as present if they occurred 'frequently' or 'almost always'. For these analyses, our subject pool was drawn from 6-12 year old Hispanic and Caucasian children who were among the first 240 subjects to complete overnight polysomnography. We attempted to select 25 
subjects with a respiratory disturbance index (RDI) less than 5.0 (low RDI group), and 25 with an RDI greater than 5.0 (high RDI group). We ultimately enrolled 27 subjects with low RDI, and 23 with a high RDI (Table 1 ). The cohort included 29 males and 21 females, with 20 Caucasians and 30 Hispanics. Our subject group is representative of the TuCASA cohort as a whole with regard to age, gender, ethnicity and anthropometric distribution. Of the subjects selected for study, 10 snored, 9 had excessive daytime sleepiness, and 13 had insomnia; but there were no correlations between the RDI or OAHI and the incidence of these self-reported symptoms.

\section{Polysomnography}

Children underwent unattended home polysomnography [17] using the Compumedics PS-2 system (Abbotsford, Victoria, Australia). The following signals were obtained: $\mathrm{C}_{3} / \mathrm{A}_{2}$ and $\mathrm{C}_{4} / \mathrm{A}_{1}$ electroencephalogram (EEG), right and left electrooculogram, a bipolar submental electromyogram, thoracic and abdominal displacement (inductive plethysmography bands), airflow (nasal/oral thermocouple), nasal pressure, electrocardiogram (single bipolar lead), snoring (microphone attached to a vest), body position (Hg gauge sensor), pulse oximetry (Nonin, Plymouth, MN) and ambient light (sensor attached to the vest to record on/off). Using Compumedics W-Series Replay, v 2.0, release 22, sleep stages were scored according to standard criteria [18]. The respiratory disturbance index (RDI) was defined as the number of respiratory events (apneas and hypopneas) per hour of the total sleep time irrespective of any associated oxygen desaturation or arousal. Polysomnograms with less than 4 hours of scorable oximetry were classified as failed studies and were repeated if the participant consented. Central apneas were scored if both airflow and thoracoabdominal effort were absent. However, central events that occurred after movement were not included. Obstructive apneas were identified if the airflow signal decreased to below $25 \%$ of the "baseline amplitude". Hypopneas were scored if the magnitude of any ventilation signal decreased below approximately 70\% of the "baseline" amplitude (see Critique of Methods section in the Discussion). Although the polysomnographic montage included monitoring of nasal pressure, we elected to not use this parameter to identify sleep disordered breathing events because experience with this technique in children is quite limited. In addition, some children were unable to tolerate wearing the nasal cannula so that scorable data was not available for all of the subjects. Thus, scoring of respiratory events was based on the thermistor and/or the inductance plethysmography signal.

The RDI that we routinely compute includes central apneas as well as obstructive apneas and hypopneas [17]. Based on the clinical and physiological uncertainty of cen- tral apneas in children $[1,19]$ we subtracted central events from the RDI to derive the OAHI. In our subjects this index represents primarily hypopneas, because only 13 of the subjects showed frank obstructive apneic events during their sleep study. The number of frank obstructive events ranged from $0.1-0.8$ per hour, except for one subject that averaged 7 obstructions per hour.

\section{Experimental protocol}

Participants were studied between 9:00 AM and 4:00 PM, and were instructed to refrain from caffeinated beverages and food for one hour prior to the time of their scheduled experiment. Subjects were studied while seated and wore audio headphones and watched movies throughout the entire protocol. Analog waveforms from transducers monitoring expiratory flow, mask pressure and the fractional concentrations of $\mathrm{O}_{2}$ and $\mathrm{CO}_{2}$ were passed through an analog-to-digital converter (Spike II, Cambridge Electronic Design), sampled at $2500 \mathrm{~Hz}$ per channel, and stored on the hard drive of an IBM-compatible computer (details of the measurements and equipment are given below). Estimated oxygen saturation of arterial blood was monitored and recorded manually in all studies with a pulse oximeter (Ohmeda). The $\mathrm{SaO}_{2}$ in the most severe hypoxic trial $\left(14 \%\right.$ inspired $\left.\mathrm{O}_{2}\right)$ ranged between 78 and $96 \%(91.5 \pm 3 \%)$.

After the mask was sufficiently fit to the subject, they were instructed to relax and began watching the movie of their choice. Each subject received either the hypoxic or hypercapnic series randomly, and the presentation of gas mixtures within the hypoxic or hypercapnic trials was also randomized. The investigators were blinded to the OAHI status of the subject when conducting experiments. For hyperoxic hypercapnia the subjects breathed from humidified Douglas bags filled with 3, 5 or $7 \% \mathrm{CO}_{2}$ in $\mathrm{O}_{2}$. Subjects started by breathing humidified room air for 3-5 minutes, and then breathed, in succession, each of the three $\mathrm{CO}_{2}-\mathrm{O}_{2}$ mixtures for 3 minutes each, and recovered by breathing room air. Isocapnic hypoxia was also initiated by 3-5 minutes of room air breathing, followed by breathing each of the 16 and $14 \% \mathrm{O}_{2}$, balance $\mathrm{N}_{2}$ mixtures. For these studies, $\mathrm{CO}_{2}$ was bled into the hypoxic mixture at a rate sufficient to keep the end-tidal $\mathrm{CO}_{2}$ levels constant, as described in detail previously [20]. At the end of the first trial, and after ventilation normalized, the breathing apparatus was removed and subjects were allowed to rest and drink water for 30-60 minutes before the mask was replaced and the remaining trial initiated and completed. In all conditions, airway occlusions were applied twice per minute, to obtain measurements of $\mathrm{P}_{0.1}$. 
Table I: Age, race, respiratory disturbance index (RDI), OAHI, body mass index (BMI), ventilatory drive in hypoxia (Slope, $\left.\mathrm{P}_{0.1} / \mathrm{P}_{\mathrm{ET}} \mathrm{O}_{2}\right)$ and the resting $P_{E T} C_{2}(\mathrm{mmHg})$ in subjects divided into low and high $\mathrm{OAHI}$ groups. Values are means \pm SD.

\begin{tabular}{|c|c|c|c|c|c|c|c|}
\hline Group & $\mathbf{N}$ & Age (Y) & RDI & OAHI & BMI $\left(\mathbf{k g} / \mathbf{m}^{2}\right)$ & $\begin{array}{l}\text { Slope, } \mathbf{P}_{0.1} / \mathbf{P}_{\mathrm{ET}} \mathbf{O}_{2} \\
(\mathrm{cmH} 2 \mathrm{O} / \mathrm{mmHg})\end{array}$ & $\begin{array}{l}\text { Resting } P_{\mathrm{ET}} \mathrm{CO}_{2} \\
(\mathrm{mmHg})\end{array}$ \\
\hline Low OAHI & 27 & $8.6 \pm 1(6-11)$ & $4.4 \pm 5(1-13)$ & $3.1 \pm 0.8(1.2-4.5)$ & $18.4 \pm 5(13.4-35)$ & $155 \pm 27(0-555)$ & $42.5 \pm 0.6(39.1-48.1)$ \\
\hline High OAHI & 23 & $9.3 \pm 5(8-12)$ & $14.6 \pm 14(6.5-72.4)$ & $12 \pm 10(5.9-52)$ & $19 \pm 4(12.6-26)$ & $83 \pm 20(0-330)$ & $44 \pm 0.7(39.4-54.9)$ \\
\hline$P$ value, low vs. high & & 0.67 & $<0.001$ & $<0.001$ & 0.74 & 0.037 & 0.066 \\
\hline
\end{tabular}

\section{Measurement of pulmonary ventilation, inspired and expired gas concentrations and $\boldsymbol{P}_{\mathbf{0 . 1}}$}

Subjects breathed through a tight fitting mask that covered the nose and mouth, and that allowed free breathing through either the oral or nasal airway (Hans- Rudolph Pediatric rubber face mask). The mask was checked for leaks by instructing the subjects to hyperventilate while an investigator looked for leaks by sampling $\mathrm{CO}_{2}$ around the mask seal. When leaks were noted, they were sealed with medical grade putty (Theraputty, Pro-Med Products, Atlanta, GA, USA). The end-tidal $\mathrm{CO}_{2}$ on inspiration returned to zero under all conditions, indicating that the system dead space was sufficiently low to prevent rebreathing.

A low dead space non-rebreathing valve (Hans Rudolph 2600) was attached to the mask, and a short length of tubing and a pneumotachometer (Hans-Rudolph 4700) were placed on the expiratory side of the breathing valve for the measurement of expiratory airflow. The pressure drop across the pneumotachometer was measured with a differential pressure transducer with a $\pm 2.5 \mathrm{cmH}_{2} \mathrm{O}$ diaphragm (Validyne MP 45). The pneumotachometer was calibrated with a precision Matheson Rotameter before each experiment. The respiratory period was measured from the flow signal, and used to compute breathing frequency (f). Expired flow was integrated by the computer off-line to derive expired tidal volume $\left(\mathrm{V}_{\mathrm{T}}\right)$, which was converted from ambient temperature, pressure and humidity conditions (ATPS) to body temperature, pressure and humidity conditions (BTPS), with the assumption that body temperature was $37^{\circ} \mathrm{C}$. Expired ventilation $\left(\mathrm{V}_{\mathrm{E}}\right)$ was computed offline as the product of $\mathrm{V}_{\mathrm{T}}$ and $\mathrm{f}$. Breath-by-breath values of $\mathrm{CO}_{2}$ and $\mathrm{O}_{2}$ were measured with rapidly responding analyzers (Ametek), which were connected to the non-rebreathing valve by small-bore tubing. The output of the analyzers was digitized and used to compute the end-tidal levels of $\mathrm{CO}_{2}$ and $\mathrm{O}_{2}$. Mask pressure was measured by connecting a short length of PE 200 tubing to the center of the non-rebreathing valve, and attaching the opposite end to a differential pressure transducer with $\mathrm{a} \pm 56 \mathrm{~cm} \mathrm{H}_{2} \mathrm{O}$ diaphragm (Validyne MP 45).
For the measurement of $\mathrm{P}_{0.1}$, a Hans-Rudolph automated balloon valve was attached to the inspiratory side of the non-rebreathing valve. The balloon was connected to a compressed air source, and was inflated or deflated with a solenoid valve and vacuum pump, respectively. The computer controlled activation and deactivation of the solenoid valve and pump. The inspiratory port was occluded during expiration, and the occlusion was maintained for about $200 \mathrm{~ms}$ into the ensuing inspiration, allowing sufficient time to obtain measurements of $\mathrm{P}_{0.1}$ [7]. The computer measured the drop in mask pressure exactly 0.1 seconds after the onset of the occluded inspiratory effort, and denoted this value as $\mathrm{P}_{0.1}$.

\section{Data processing and statistical analysis}

Six-to-ten breaths, obtained over the last 30-40 seconds at each level of isocapnic hypoxia and hyperoxic hypercapnia, were used to calculate average values of $\mathrm{V}_{\mathrm{T}}, \mathrm{f}, \mathrm{V}_{\mathrm{E}}$ and the partial pressures of end-tidal $\mathrm{O}_{2}\left(\mathrm{P}_{\mathrm{ET}} \mathrm{O}_{2}\right)$ and $\mathrm{CO}_{2}$ $\left(\mathrm{P}_{\mathrm{ET}} \mathrm{CO}_{2}\right)$. All $\mathrm{P}_{0.1}$ values obtained in each condition were averaged, so that each subject had a single $\mathrm{P}_{0.1}$ measurement for each of the experimental conditions. All $\mathrm{P}_{0.1}$ values were expressed in units of $\mathrm{cmH}_{2} \mathrm{O}$.

The $V_{E}$ values for each subject were divided by the subject's body surface area (BSA, units of $\mathrm{m}^{2}$ ) to account for the large differences in size (and hence tidal volume) over the 6 -year age range of our pediatric subject population. This analysis allowed us to compare the hypoxic and hypercapnic ventilatory responses of our subjects with previously published results in children of various ages.

To determine if the severity of SDB correlates with ventilatory drive, we first plotted the $\mathrm{P}_{0.1}-\mathrm{P}_{\mathrm{ET}} \mathrm{O}_{2}$ and $\mathrm{P}_{0.1}-\mathrm{P}_{\mathrm{ET}} \mathrm{CO}_{2}$ relation for each subject, and computed the slope of the relation as an index of hypoxic and hypercapnic ventilatory drive. For the $\mathrm{P}_{0.1}-\mathrm{P}_{\mathrm{ET}} \mathrm{CO}_{2}$ relation we used linear regression analysis to determine the slope. The P0.1 response to hypoxia is expressed as the value "A", which defines the slope of the hyperbolic relation obtained by plotting $\mathrm{P}_{0.1}$ vs. $\mathrm{P}_{\mathrm{ET}} \mathrm{O}_{2}[21]$ :

$\mathrm{P}_{0.1}=\mathrm{P}_{0.1(0)}+\mathrm{A} /\left(\mathrm{P}_{\mathrm{ET}} \mathrm{O}_{2}-32\right)$ 
$\mathrm{P}_{0.1(0)}$ is the estimated asymptote for $\mathrm{P}_{0.1}$ as a function of $\mathrm{P}_{\mathrm{ET}} \mathrm{O}_{2}$, and $\mathrm{A}$ is the slope, with higher values indicating greater hypoxic responsiveness We then plotted each subject's hypercapnic and hypoxic response slope against their OAHI, and subjected the data to a linear regression analysis. To determine if $\mathrm{CO}_{2}$ retention was correlated with the OAHI, we plotted the resting level of $\mathrm{P}_{\mathrm{ET}} \mathrm{CO}_{2}$ for each subject against his or her OAHI. We used a simple linear regression model followed by analysis of variance (ANOVA, Sigma Stat 3.0) to determine if the relation was statistically significant, with significance defined as a $\mathrm{P}$ value $<0.05$.

Regression analysis revealed that both resting $\mathrm{P}_{\mathrm{ET}} \mathrm{CO}_{2}$ and the $\mathrm{P}_{0.1}-\mathrm{P}_{\mathrm{ET}} \mathrm{O} 2$ relation correlated significantly with the OAHI. However, the correlation coefficients were not particularly high, so we also examined the influence of OAHI on $\mathrm{CO}_{2}$ retention and the $\mathrm{P}_{0.1}-\mathrm{P}_{\mathrm{ET}} \mathrm{O}_{2}$ relation by dividing the subjects into high and low OAHI groups, and comparing the average values with ANOVA and the Student Neumann-Keuls posthoc analysis (see Table 3 ).

\section{Results}

\section{General observations}

Subject characteristics are given in Table 1. As indicated in Methods, we studied slightly more males than females, and more Hispanics than Caucasians. There were no gender or ethnicity differences for any variables, so the data were combined into a single group of subjects. The age range of the participants is given in Table 1, along with the average body mass index (BMI) for each age group. All subjects had lung function values that were within the normal range.

The range of RDI and OAHI values are given in Table 1. Note that the average RDI in both groups exceeds the OAHI, owing to the inclusion of central apneic events in the former. Since there is no agreed upon OAHI cut point that defines clinically relevant obstructive sleep apnea in children, we chose to express indices of respiratory drive as a function of the OAHI. This allowed us to test the hypothesis that the OAHI and the magnitude of the hypoxic and hypercapnic ventilatory drive are independent. The OAHI was independent of age and BMI, although it was significantly correlated with height $(\mathrm{r}=0.32, \mathrm{P}=$ 0.024). However, neither hypercapnic nor hypoxic responses correlated with height, indicating that ventilatory drive in hypoxia or hypercapnia is independent of height.

Ventilatory and $\boldsymbol{P}_{\mathbf{0 . I}}$ responses to hypercapnia and hypoxia The BSA-corrected ventilatory response to three levels of hyperoxic hypercapnia and two levels of isocapnic hypoxia for all subjects is shown in the top and bottom panels of Figure 1. The standard error of the estimate
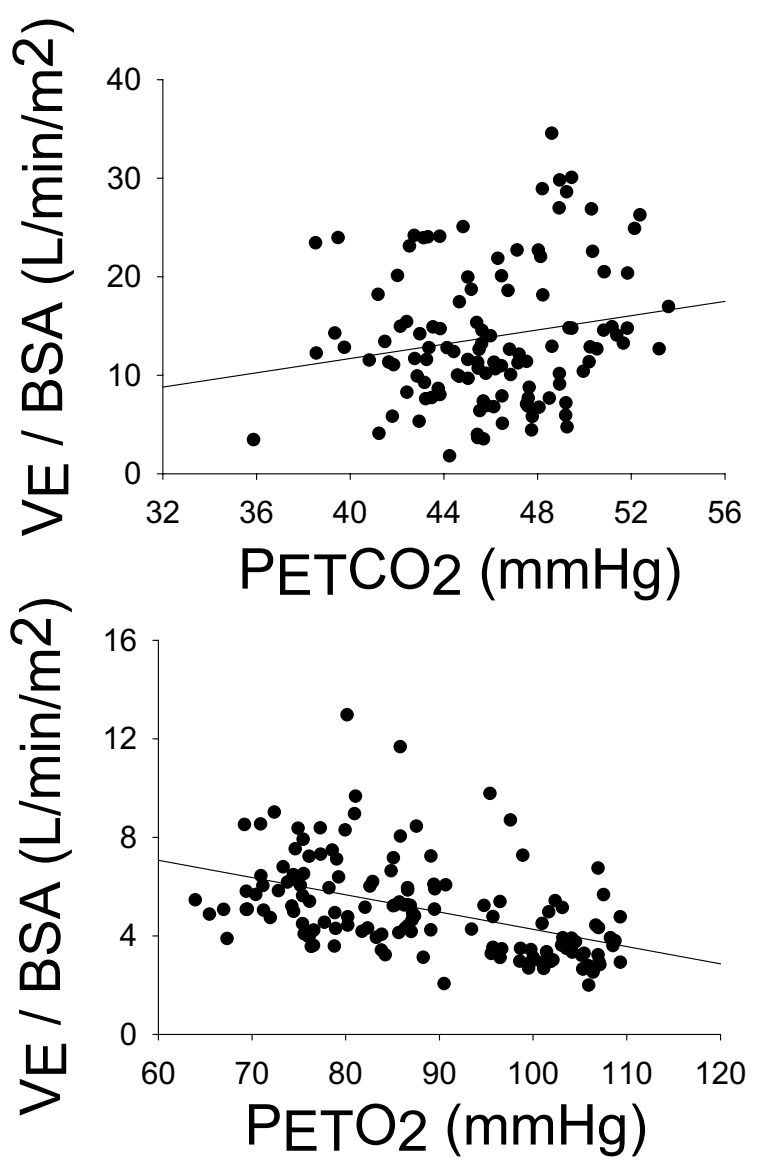

Figure I

Expired minute ventilation $\left(\mathrm{V}_{\mathrm{E}}\right)$ corrected for body surface area (BSA), as a function of the partial pressure of end-tidal $\mathrm{CO}_{2}\left(\mathrm{P}_{\mathrm{ET}} \mathrm{CO}_{2}\right)$ (top panel) or end-tidal $\mathrm{O}_{2}\left(\mathrm{P}_{\mathrm{ET}} \mathrm{O}_{2}\right)$ (bottom panel). Each data point represents the average value computed during room air breathing and at each of three levels of hypercapnia and two levels of hypoxia in each of the subjects (see Methods).

(SEE) of the regression analysis was 6.9 for hypercapnia ( $\mathrm{r}$ $=0.18, \mathrm{P}=0.053)$, and 1.7 for hypoxia $(\mathrm{r}=0.46, \mathrm{P}<$ $0.001)$. The $P_{0.1}$ response rose significantly with rising $\mathrm{CO}_{2}$ and falling $\mathrm{O}_{2}$ (Fig. 2), with the responses roughly parallel to the ventilatory response $(r=0.46$ in hypercapnia and 0.33 in hypoxia, with $\mathrm{P}<0.001$ for both, Fig. 2). The occlusion pressure $-\mathrm{P}_{\mathrm{ET}} \mathrm{CO}_{2}$ relation was significant and less variable than the $\mathrm{V}_{\mathrm{E}}-\mathrm{P}_{\mathrm{ET}} \mathrm{CO}_{2}$ relation (SEE $2.17 \mathrm{vs}$. 6.9), and the correlation coefficient was 0.46 as opposed to 0.18 . Similarly, the occlusion pressure $-\mathrm{P}_{\mathrm{ET}} \mathrm{O}_{2}$ relation was less variable than the $\mathrm{V}_{\mathrm{E}}-\mathrm{P}_{\mathrm{ET}} \mathrm{O}_{2}$ relation (SEE 1.15 vs. $1.7)$, although the correlation was stronger in the latter case $(0.33$ vs. 0.46$)$. 

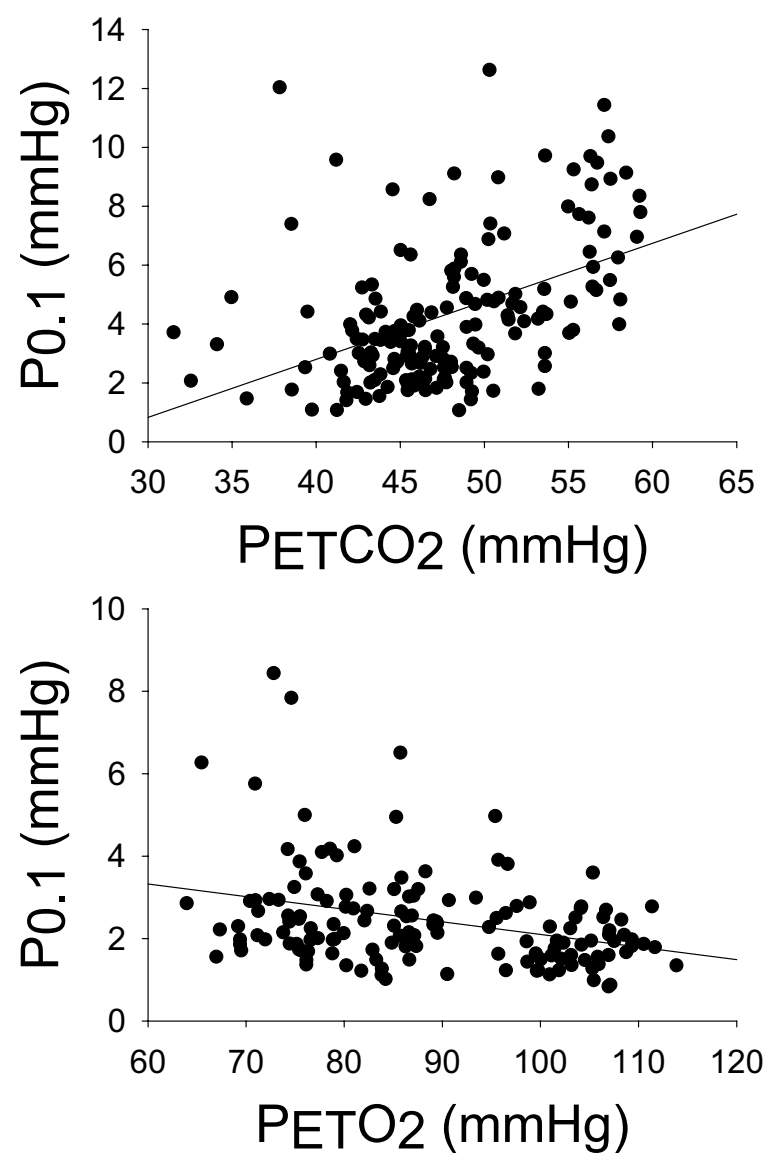

Figure 2

Mouth occlusion pressure $\left(\mathrm{P}_{0.1}\right)$ as a function of the partial pressure of end tidal $\mathrm{CO}_{2}\left(\mathrm{P}_{\mathrm{ET}} \mathrm{CO}_{2}\right)$ (top panel) or end-tidal $\mathrm{O}_{2}\left(\mathrm{P}_{\mathrm{ET}} \mathrm{O}_{2}\right)$ (bottom panel). Each data point represents the average value computed during room air breathing and at each of three levels of hypercapnia and two levels of hypoxia in each of the subjects (see Methods).

\section{Relation between resting $\mathrm{P}_{\mathrm{ET}} \mathrm{CO}_{2}$ and the $\mathrm{OAHI}$}

Although the average resting $\mathrm{P}_{\mathrm{ET}} \mathrm{CO}_{2}$ in the high and low OAHI groups was not significantly different (Table 1), there was a significant correlation between resting $\mathrm{P}_{\mathrm{ET}} \mathrm{CO}_{2}$ with OAHI $(r=0.30, \mathrm{SEE}=7.6, \mathrm{P}=0.03)$, suggesting a tendency for resting $\mathrm{CO}_{2}$ retention in subjects with a high OAHI (Fig. 3). The bottom panel of Figure 3 shows that the relationship is stronger when the outlier with the OAHI value of 52 is removed from the data set $(r=0.35$, $\mathrm{SEE}=4.4, \mathrm{P}=0.015)$, suggesting that the results are not biased by this extreme value; rather, they are improved when this outlier is eliminated from the data set.
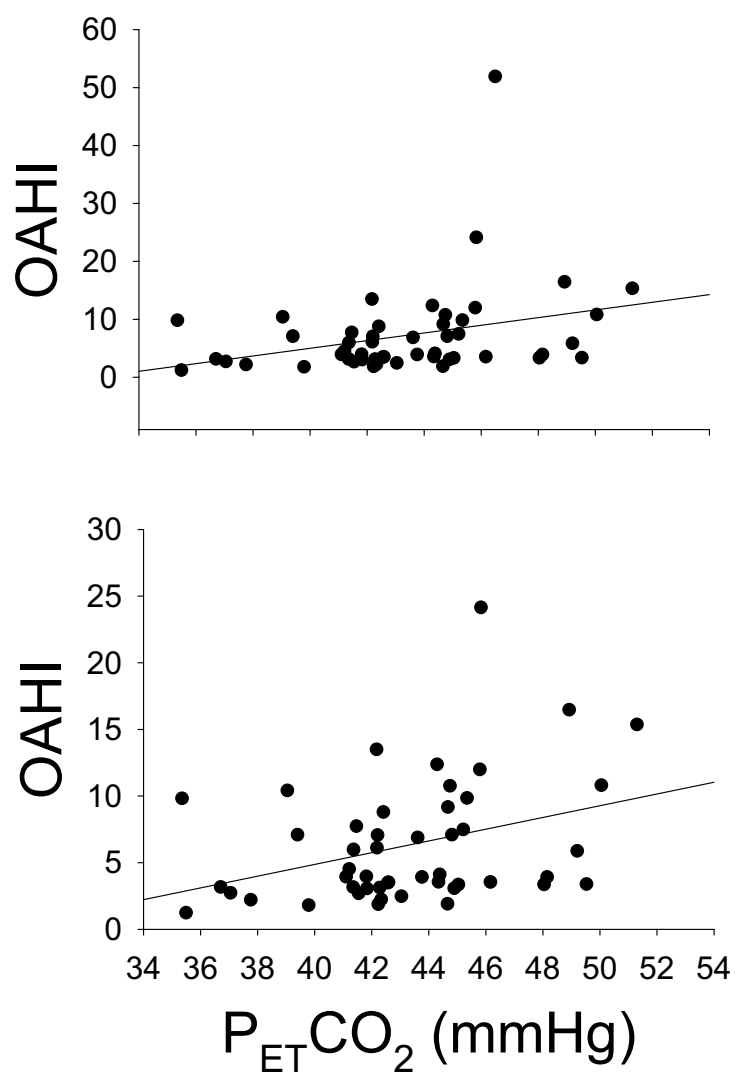

Figure 3

Relation between the partial pressure of end tidal $\mathrm{CO}_{2}$ $\left(\mathrm{P}_{\mathrm{ET}} \mathrm{CO}_{2}\right)$ measured under resting, baseline conditions and the obstructive apnea-hypopnea index $(\mathrm{OAHI})$. The top panel represents data from all subjects, and the bottom panel shows that the relation is strengthened when the outlier with the very high $\mathrm{OAHI}$ is removed from the data set (see Text for details). Measurements were made while the subjects respired room air, and after they were given several minutes to become accustomed to the breathing mask and associated measurement equipment.

\section{Relation between OAHI and ventilatory drive}

We used the mouth occlusion pressure response to hypoxia and hypercapnia to estimate ventilatory drive. The $\mathrm{P}_{0.1}$ during quiet breathing prior to the hypoxic and hypercapnic challenges averaged $2.1 \mathrm{cmH}_{2} \mathrm{O}$, with a range of $0.8-4.2, \mathrm{~N}=92$. Changes in mouth occlusion pressure and expired airflow in response to one level of hypoxia and one level of hypercapnia are shown in Figure 4 for two subjects, one with a low OAHI (top) and one with a high OAHI (bottom). In the low OAHI subject, both occlusion pressure $\left(\mathrm{P}_{0.1}\right.$, vertical line on mouth pressure tracing) and ventilation rose in response to hypoxia and 


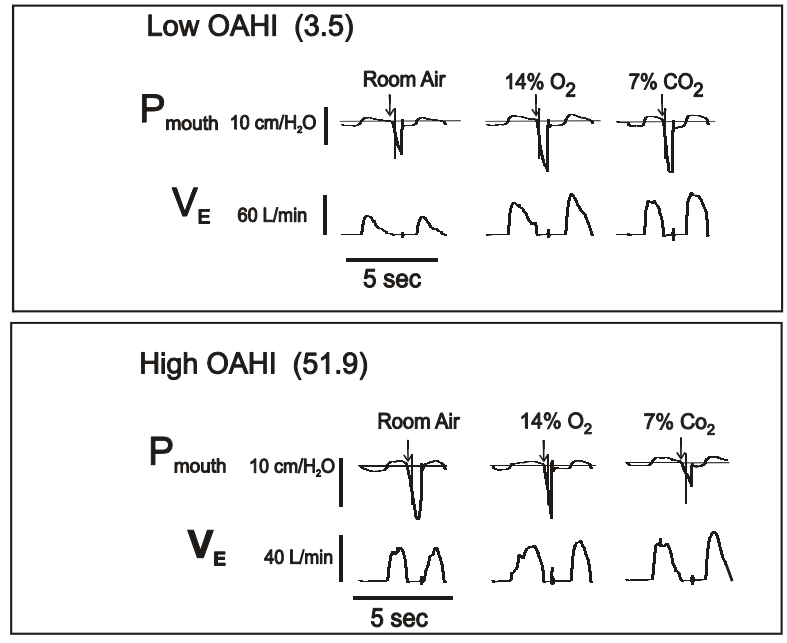

Figure 4

Sample records from two subjects showing $V_{E}$ and mouth occlusion pressure $\left(\mathrm{P}_{0.1}\right)$ responses to room air breathing, and severe hypoxia and hypercapnia. The top panel shows records from a subject with a low OAHI, and the bottom panel from the subject with the highest $\mathrm{OAHI}$ observed in our population.

hypercapnia. In contrast, the high OAHI subject showed blunted, or even diminished, ventilatory and $\mathrm{P}_{01}$ responses. This subject had the highest OAHI of all subjects, and her responses were remarkable. As explained in methods, the dependence of the OAHI on hypercapnic and hypoxic ventilatory drive was examined by plotting the slope of the $\mathrm{P}_{0.1}-\mathrm{P}_{\mathrm{ET}} \mathrm{CO}_{2}$ and $\mathrm{P}_{0.1}-\mathrm{P}_{\mathrm{ET}} \mathrm{O}_{2}$ relation for each subject against their corresponding OAHI. As shown in Figure 5, the hypercapnic occlusion pressure response was not significantly related to the OAHI, whether the outlier was included (top panel) or not (bottom panel). In contrast, the hypoxic occlusion pressure response was significantly related to the OAHI $(\mathrm{r}=0.31, \mathrm{SEE}=7.8, \mathrm{P}=$ $0.04)$, as shown in the top panel of Figure 6 . When the statistical outlier was removed (Fig. 6, bottom panel), the relationship improved $(\mathrm{r}=0.37$, SEE $=4.5, \mathrm{P}=0.015)$. As indicated above, the $\mathrm{V}_{\mathrm{E}} / \mathrm{P}_{\mathrm{ET}} \mathrm{O}_{2}$ and $\mathrm{V}_{\mathrm{E}} / \mathrm{P}_{\mathrm{ET}} \mathrm{CO}_{2}$ slopes were more variable than the occlusion pressure response slopes. Nevertheless, we examined the relation between the ventilatory response slopes and the OAHI. The $\mathrm{V}_{\mathrm{E}} /$ $\mathrm{P}_{\mathrm{ET}} \mathrm{CO}_{2}$ - OAHI relation revealed a correlation coefficient of $0.15(\mathrm{P}=0.37)$, and $\mathrm{V}_{\mathrm{E}} / \mathrm{P}_{\mathrm{ET}} \mathrm{O}_{2}$ - OAHI revealed a correlation coefficient of 0.24 and a $P$ value of 0.10 .

\section{Comparison of subjects in high and low $\mathrm{OAHI}$ groups}

Because the slope of the P0.1- $\mathrm{P}_{\mathrm{ET}} \mathrm{O}_{2}$ relation and the resting $\mathrm{P}_{\mathrm{ET}} \mathrm{CO}_{2}$ both correlated significantly with the OAHI,
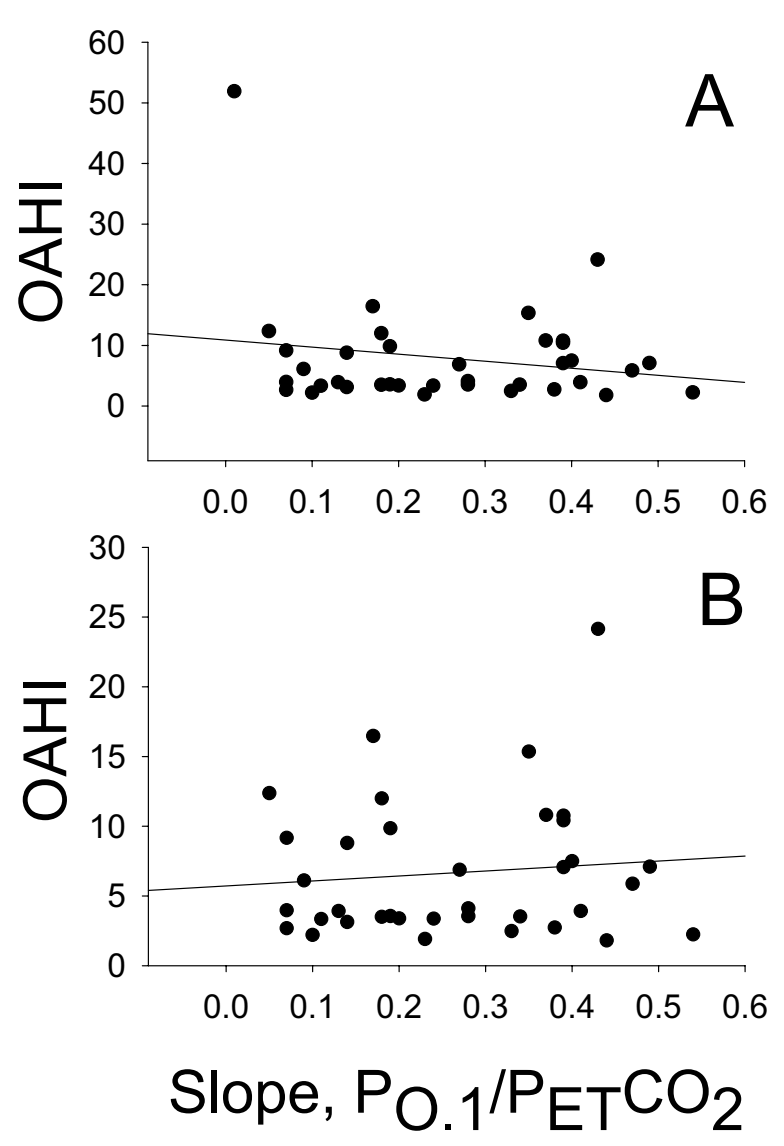

Figure 5

Correlation between each subject's $\mathrm{OAHI}$ and the slope of the $\mathrm{P}_{0.1} / \mathrm{P}_{\mathrm{ET}} \mathrm{CO}_{2}$ curve. The top panel represents data from all subjects, and the bottom panel shows that the relation is strengthened when the outlier with the very high OAHI is removed from the data set (see Text for details). The slope of the $\mathrm{P}_{0.1} / \mathrm{P}_{\mathrm{ET}} \mathrm{CO}_{2}$ curves were obtained for each subject during the response tests, as described in Methods.

we divided the subjects into low $(\mathrm{N}=27)$ and high OAHI groups $(\mathrm{N}=23)$ and compared the group average ventilatory drive (using the slope of the $\mathrm{P}_{0.1} / \mathrm{P}_{\mathrm{ET}} \mathrm{O}_{2}$ relation, as above) and resting $\mathrm{P}_{\mathrm{ET}} \mathrm{CO}_{2}$ values (Table 1). The "low" group had an OAHI value of $3.1 \pm 0.8$ (mean $\mathrm{SD}$ ), and the "high" group had an OAHI of $12.0 \pm 9.6(\mathrm{P}<0.001)$. The slope of the hypoxic response was significantly lower in the high OAHI group $(82.8 \pm 91)$ compared to the low OAHI group $(155 \pm 130), \mathrm{P}=0.037$. The resting $\mathrm{P}_{\mathrm{ET}} \mathrm{CO}_{2}$ was higher in the high OAHI group, but the difference was not significant. However, the P value was 0.066 , and we found that removing the lowest $\mathrm{P}_{\mathrm{ET}} \mathrm{CO}_{2}$ value from the high OAHI group resulted in statistical significance. 

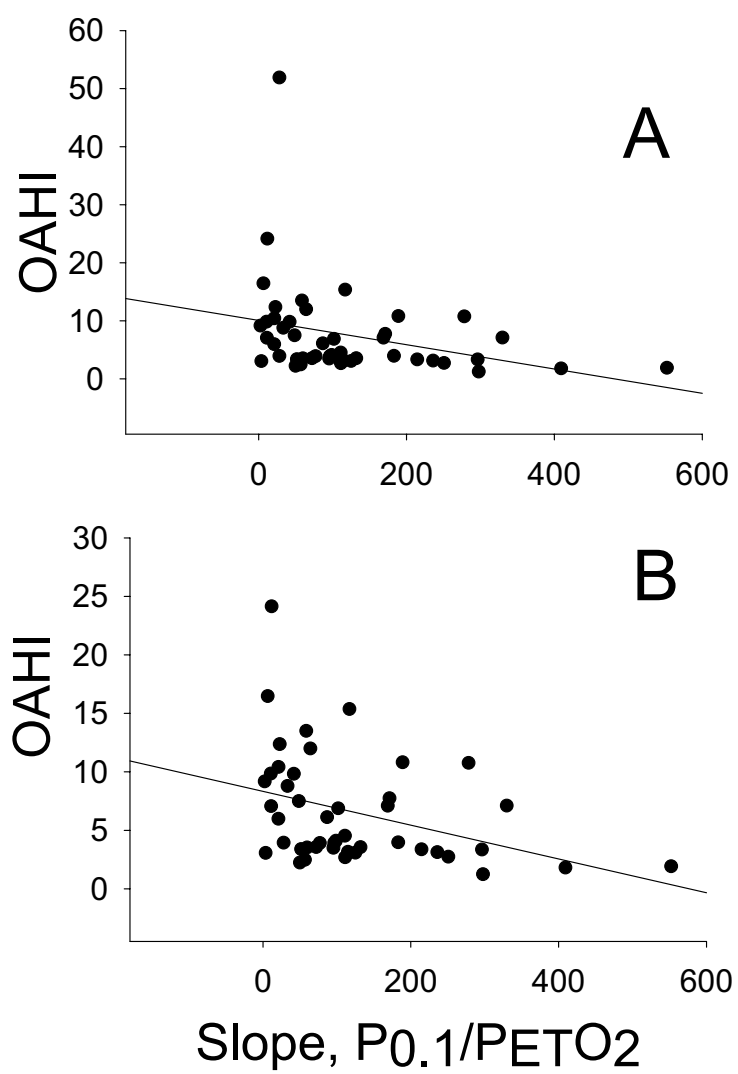

\section{Figure 6}

Correlation between each subject's $\mathrm{OAHI}$ and the slope of the $\mathrm{P}_{0.1} / \mathrm{P}_{E T} \mathrm{O}_{2}$ curve. The top panel represents data from all subjects, and the bottom panel shows that the relation is strengthened when the outlier with the very high OAHI is removed from the data set (see Text for details). The slope of the $\mathrm{P}_{0.1} / \mathrm{P}_{E T} \mathrm{O}_{2}$ curves were obtained for each subject during the response tests, as described in Methods.

\section{Discussion}

The results of this study in awake, 6-12 year old children show a significant, positive correlation between the OAHI and the resting $\mathrm{P}_{\mathrm{ET}} \mathrm{CO}_{2}$, and a significant inverse relationship between the OAHI and the mouth occlusion pressure response to hypoxia. These data suggest that children with high OAHI values retain $\mathrm{CO}_{2}$ and have reduced hypoxic ventilatory drive.

\section{Critique of methods}

Although methodological issues specific to each experimental observation are discussed where appropriate, there are three issues that have a major impact on the interpretation of our results, and they will be discussed here. The first is our computation of the obstructive apnea hypopnea index (OAHI). We acknowledge that our definition of hypopnea did not incorporate an arousal, or desaturation criteria. Although such criteria have been recommended [22], more recent reviews have noted that there is no standard definition of hypopnea in children $[23,24]$. Recently, we have demonstrated that using our current definition, there is an association between RDI and several clinical outcomes in children [25]. We also wish to emphasize that the definition of hypopnea employed in this study was used to describe a spectrum of SDB ranging from none/mild to severe, and not to implicate a specific value as constituting disease. Thus, the precise definition utilized is not important if it provides a relatively consistent description of SDB severity. To demonstrate that this is true in the current study, we have performed a correlation matrix using the hypopnea definition employed in our study and others that required an oxygen desaturation event of $2-4 \%$. These indices were highly intercorrelated with $r=0.82-0.95$, indicating that use of a different event definition would only change the absolute values of the OAHI, and not alter any assessment of relative disease severity in these children. Furthermore, as demonstrated by Tang et al [19], definitions of sleep disordered breathing are highly intercorrelated so that the use of different definitions of sleep disordered breathing generally results in consistent ranking of subjects according to sleep disordered breathing severity. These observations have been replicated in preliminary analyses of the TuCASA cohort (unpublished data).

It is also important to point out that, unlike the more commonly used RDI, the OAHI as computed herein does not include central apneas. We chose to exclude central apneas because they are very common even in children without sleep disordered breathing $[26,27]$. Consistent with this proposition are the results of a recent study by Tang et al. [19], showing that central apneas are a major source of variability in summary indices of sleep disordered breathing in children. From these observations Tang et al [19] suggest that central apneas should not be reported together with hypopneas and obstructive events. Tang et al. [19] also showed that central apneas occur six times more frequently than obstructive events in children, and the data from our more limited subject population is consistent with this (our OAHI averaged 1.89 events per hour of sleep, compared to our central apnea index of 7.2 events per hour). These observations support the hypothesis that central apneas are common in sleeping children irrespective of coexisting sleep disordered breathing. Accordingly, we have chosen to use the OAHI to estimate the severity of sleep disordered breathing and to test our hypothesis that sleep disordered breathing severity is correlated with ventilatory drive. 
The second issue is the estimation of ventilatory drive during wakefulness as opposed to sleep. The ventilatory response to $\mathrm{CO}_{2}$ is highly variable during sleep, and in rapid eye movement (REM) sleep the slope of the response is significantly reduced compared to wakefulness, with no change in the apnea point [28]. Whether or not sleep would affect the ventilatory drive more in children with sleep disordered breathing compared to control subjects is unknown, although this is a very important question. Nevertheless, demonstrating a reduced ventilatory drive during wakefulness in children with sleep-disordered breathing tells us that altered ventilatory control is at the least associated with this condition.

The third methodological issue is our use of $\mathrm{P}_{\mathrm{ET}} \mathrm{O}_{2}$ rather than the more conventional $\mathrm{SaO}_{2}$ to estimate hypoxic ventilatory drive. We analyzed our data using $\mathrm{P}_{\mathrm{ET}} \mathrm{O}_{2}$ for two reasons. First, in our hands the correlation between $\mathrm{P}_{\mathrm{ET}} \mathrm{O}_{2}$ and $\mathrm{P}_{0.1}$ was better than the $\mathrm{SaO}_{2}-\mathrm{P}_{0.1}$ relation. Second, the measurement of $\mathrm{P}_{\mathrm{ET}} \mathrm{O}_{2}$ is more precise and physically meaningful than the measurement of $\mathrm{SaO}_{2}$, which reflects an often-crude estimate of $\mathrm{SaO}_{2}$ that can vary considerably depending on skin perfusion, movement artifact and other variables [29].

\section{Relation between resting $\mathrm{P}_{\mathrm{ET}} \mathrm{CO}_{2}$ and the $\mathrm{OAHI}$}

The observation that resting $\mathrm{P}_{\mathrm{ET}} \mathrm{CO}_{2}$ during wakefulness is significantly related to the OAHI is consistent with other data showing hypoventilation and $\mathrm{CO}_{2}$ retention in adults and children with sleep disordered breathing. Gold et al. [2] showed hypoventilation leading to $\mathrm{CO}_{2}$ retention and mild hypoxemia in adults with severe sleep disordered breathing. Waters et al. [14] showed a significantly higher baseline $\mathrm{P}_{\mathrm{ET}} \mathrm{CO}_{2}$ (42 vs. $49 \mathrm{mmHg}$ ) during wakefulness in children with sleep disordered breathing. Marcus et al. [5] did not report the $\mathrm{CO}_{2}$ level during quiet breathing in wakefulness, but they did show that children with sleep disordered breathing retained significant $\mathrm{CO}_{2}$ during sleep. The weight of the available evidence suggests that children with sleep disordered breathing hypoventilate during wakefulness, and our experiments extend the concept by demonstrating that the magnitude of hypoventilation correlates significantly with the severity of sleep disordered breathing. The reason that children with sleep-disordered breathing retain $\mathrm{CO}_{2}$ during quiet breathing is uncertain. There have been anecdotal suggestions that enlarged tonsils, and thus a narrow pharyngeal airway, predisposes the children to nasal breathing, which in turn leads to hypoventilation through the high-resistance nasal pathway. Although this could explain our results because the subjects breathed oronasally through a mask, it cannot explain the results of Marcus et al. [5] as their subjects breathed through a mouthpiece, nor the results of Waters et al. [14] wherein subjects breathed through an endotracheal tube while under the influence of $1 \%$ halothane in oxygen. Additional evidence against a mechanical influence on the resting $\mathrm{CO}_{2}$ level comes from a recent study showing that adenotonsillectomy failed to abolish resting $\mathrm{CO}_{2}$ retention during wakefulness in children with sleep disordered breathing [15]. Thus the resting $\mathrm{CO}_{2}$ retention during wakefulness in the subjects with relatively high OAHI values may be due to perturbed central ventilatory control, rather than altered airway or lung tissue mechanics.

Resting $\mathrm{CO}_{2}$ retention in children with relatively high OAHI may result from desensitization of central chemoreceptors secondary to repeated episodes of hypoventilation throughout the evening [30]. It is also possible that a reduced resting ventilatory drive predisposes children to sleep disordered breathing, as minor airway narrowing and hypoventilation during sleep fail to stimulate the respiratory system enough to prevent hypopneas and/or apneic events. It is obvious that more detailed studies are needed to establish the mechanism and consequences of the resting $\mathrm{CO}_{2}$ retention during wakefulness in children with sleep disordered breathing.

\section{Ventilatory response to hyperoxic hypercapnia}

As a group, our subjects showed a normal ventilatory response to $\mathrm{CO}_{2}$ (Fig. 2). The average, BSA-corrected $\mathrm{CO}_{2}$ sensitivity of our subjects was $0.45 \mathrm{~L} / \mathrm{min} / \mathrm{m}^{2} / \mathrm{mmHg} \mathrm{CO}_{2}$ and the "uncorrected" sensitivity averaged $0.81 \mathrm{~L} / \mathrm{min} /$ $\mathrm{mmHg} \mathrm{CO}_{2}$. The latter values are very similar to those reported by Gozal et al. [31] in children $(0.87 \mathrm{~L} / \mathrm{min} /$ $\mathrm{mmHg}$ ). In contrast, Marcus et al. [5] reported a value of $1.5 \mathrm{~L} / \mathrm{min} / \mathrm{m}^{2} / \mathrm{mmHg} \mathrm{CO}_{2}$, roughly three fold higher than the average for our subjects. This is likely the result of technical differences, as Marcus et al. [5] used a $\mathrm{CO}_{2}$ rebreathing technique as opposed to our quasi-steady state method, and it has been shown that the rebreathing technique results in estimated hypercapnic responses 2-3 fold higher than those obtained under quasi-steady state conditions [32]. It is also possible that the use of a mouthpiece and nose clips in the study by Marcus et al. [5] contributed to the difference. Shi et al. [33] showed that mouth breathing results in higher $\mathrm{CO}_{2}$ response curves compared to nose breathing, owing to higher resistance in the latter condition. Thus, our $\mathrm{CO}_{2}$ responsiveness is within the normal range for children when the nature of the test and other methodological differences are considered.

\section{The OAHI and the mouth occlusion pressure response to hyperoxic hypercapnia}

We used the change in $\mathrm{P}_{0.1}$ as a function of $\mathrm{P}_{\mathrm{ET}} \mathrm{CO}_{2}$ to test the hypothesis that ventilatory drive in hypercapnia is related to the severity of sleep disordered breathing. We did this because the $P_{0.1}$ is less sensitive to variations in body size than minute ventilation $[7,34]$. It is possible 
that hypercapnia (or hypoxia) could increase airway resistance to a variable extent across the subject population. However, the $P_{0.1}$ is uninfluenced by airway resistance and behavioral adjustments in ventilatory output $[7,34]$. Accordingly, we chose to use the $\mathrm{P}_{0.1}$ technique to avoid these complications. Our baseline $\mathrm{P}_{0.1}$ values were within the range reported for children of similar age reported by Marcus and colleagues [8], although it is important to point out that our sample size ( 92 baseline measurements in 50 subjects) is much larger than the Marcus et al data set (six subjects, reference [8], and to our knowledge it is the largest data set of its kind. Nevertheless, we failed to find a relationship between the severity of sleep-disordered breathing (i.e., the OAHI) and the mouth occlusion pressure response to hypercapnia in wakefulness. This was in spite of our observation that the resting $\mathrm{CO}_{2}$ was significantly and positively correlated with the OAHI. The explanation for this discrepancy is not clear, although the data suggest that sleep disordered breathing results in resting $\mathrm{CO}_{2}$ retention, but unaltered sensitivity to $\mathrm{CO}_{2}$ (i.e., the slope of the response) in children. However, it is possible that if the sleep disordered breathing is untreated or fails to resolve, the $\mathrm{CO}_{2}$ sensitivity will change as the children age and the central chemoreceptors are further desensitized by chronic $\mathrm{CO}_{2}$ retention and/or chronic nocturnal asphyxia. There is evidence for this in adult patients with SDB. Lopata and Onal [3] showed that obese patients with sleep disordered breathing had diminished $\mathrm{P}_{0.1}$ responses to hypercapnia during wakefulness, and these findings were corroborated by Gold et al. [2] and Radwan et al. [35].

\section{The OAHI and the mouth occlusion pressure response to isocapnic hypoxia}

The results of the hypoxia trials showed a significant relation between the mouth occlusion pressure response to quasi-steady state isocapnic hypoxia and the OAHI. Although the relationship was not particularly strong (explaining about $9-10 \%$ of the variability), it was nonetheless statistically significant. Our findings are consistent with observations showing reduced hypoxic sensitivity in adults $[36,37]$, which may be the result of altered dopaminergic neurotransmission at the carotid body [38]. In contrast, the data in children are equivocal. Marcus et al. [5] did not show significant differences in hypoxic ventilatory drive when a group of children with sleep disordered breathing was compared to age and BMI matched control subjects. However, it is possible that a difference would have been observed by Marcus et al. [5] if they accounted for differences in the severity of the disease by computing the correlation between OAHI and hypoxic ventilatory drive. Indeed, Marcus et al. [5] point out that some of their children with sleep disordered breathing may have had blunted hypoxic drives, but the phenomenon was not revealed because of their relatively small sample size. Our correlational approach clearly shows a relationship between hypoxic ventilatory drive and the OAHI, demonstrating that a reduced hypoxic responsiveness is one of several factors that either coexists with sleep disordered breathing in children, or predisposes children to the disease.

\section{Conclusions}

We observed a reduced hypoxic ventilatory drive and resting $\mathrm{CO}_{2}$ retention in children with relatively high OAHI values, but the mechanism is not known. Whether or not diminished hypoxic drive or resting $\mathrm{CO}_{2}$ retention while awake can explain the severity of sleep-disordered breathing in this population is uncertain. Nevertheless, a reduced hypoxic ventilatory drive and resting $\mathrm{CO}_{2}$ retention are associated with sleep-disordered breathing in $6-$ 12 year old children.

\section{Competing interests}

None declared.

\section{Abbreviations}

ANOVA, analysis of variance

ATPS, ambient temperature and pressure, saturated

BMI, body mass index

BSA, body surface area

BTPS, body temperature and pressure, saturated

EEG, electroencephalogram

$\mathrm{f}$, frequency of breathing

OAHI, obstructive apnea hypopnea index

$\mathrm{P}_{0.1}$, mouth pressure measured $0.1 \mathrm{sec}$ following the onset of airway occlusion

$\mathrm{PCO}_{2}$, partial pressure of $\mathrm{CO}_{2}$

$\mathrm{P}_{\mathrm{ET}} \mathrm{CO}_{2}$, partial pressure of end-tidal $\mathrm{CO}_{2}$

$\mathrm{P}_{\mathrm{ET}} \mathrm{O}_{2}$, partial pressure of end tidal $\mathrm{O}_{2}$

RDI, respiratory disturbance index

REM, rapid eye movement

$\mathrm{SaO} 2$, estimated oxygen saturation of arterial blood

SEE, standard error of the estimate 
TuCASA, Tucson Children's Assessment of Sleep Apnea Study

$\mathrm{V}_{\mathrm{E}^{\prime}}$ expired minute ventilation

$\mathrm{V}_{\mathrm{T}}$, tidal volume

\section{Authors' contributions}

$\mathrm{RF}$ designed and supervised all aspects of the study, and wrote the manuscript; SQ assisted RF in the writing of the manuscript and also supervised the sleep studies; AJ assisted with the development of computer control of the mouth occlusion pressure measurements; KK helped with the statistical analysis and with manuscript editing; WM and JG were involved in subject screening and recruitment, and in conduct and interpretation of the sleep studies; JR and RC conducted all of the control of breathing experiments and did the initial data analysis.

\section{Acknowledgments}

The authors thank Cortnie Cherry, Jason Quan, Dan Stoker, Veronica Tapia and Jesse Winer for expert technical assistance. The study was supported by grants HL 62373 and HL 51056 . Address all correspondence to: R.F. Fregosi, Ph.D., Department of Physiology, Gittings Building, The University of Arizona, Tucson, AZ 85721-0093.

\section{References}

I. Marcus CL: Sleep-disordered breathing in children. Am J Respir Crit Care Med 200I, 164:16-30.

2. Gold AR, Schwartz AR, Wise RA, Smith PL: Pulmonary function and respiratory chemosensitivity in moderately obese patients with sleep apnea. Chest 1993, I03:1325-1329.

3. Lopata M, Onal E: Mass loading, sleep apnea, and the pathogenesis of obesity hypoventilation. Am Rev Respir Dis 1982, I 26:640-645.

4. Marcus CL, Lutz J, Carroll JL, Bamford O: Arousal and ventilatory responses during sleep in children with obstructive sleep apnea. J Appl Physiol 1998, 84:1926-1936.

5. Marcus CL, Gozal D, Arens R, Basinski DJ, Omlin KJ, Keens TG, Ward SL: Ventilatory responses during wakefulness in children with obstructive sleep apnea. Am J Respir Crit Care Med 1994, I49:715-72I.

6. Honda $\mathrm{Y}$, Ohyabu $\mathrm{Y}$, Sato M, Masuyama H, Nishibayashi $\mathrm{Y}$, Maruyama R, Tanaka Y, Nakajo I, Shirase H, Hayashida K: Hypercapnic and hypoxic ventilatory responses during growth. Jpn J Physiol I986, 36:177-187.

7. Whitelaw WA, Derenne JP, Milic-Emili J: Occlusion pressure as a measure of respiratory center output in conscious man. Respir Physiol 1975, 23:181-199.

8. Marcus CL, Lutz J, Hamer A, Smith PL, Schwartz A: Developmental changes in response to subatmospheric pressure loading of the upper airway. J Appl Physiol 1999, 87:626-633.

9. Schmidt-Nielsen Knut: Scaling-why is animal size so important? London, Cambridge University Press; 1984:24I.

10. Xie A, Skatrud JB, Dempsey JA: Effect of hypoxia on the hypopnoeic and apnoeic threshold for $\mathrm{CO}(2)$ in sleeping humans. J Physiol 200I, 535:269-278.

II. Robbins PA: Possible mechanisms that may determine the set point and sensitivities of the chemoreflexes. Adv Exp Med Biol 200I, 499:237-239.

I2. Meza S, Mendez M, Ostrowski M, Younes M: Susceptibility to periodic breathing with assisted ventilation during sleep in normal subjects. J Appl Physiol 1998, 85: 1929-1940.

13. Reeves JT, McCullough RE, Moore LG, Cymerman A, Weil JV: Sealevel PCO2 relates to ventilatory acclimatization at $4,300 \mathrm{~m}$. J Appl Physiol 1993, 75: I I I7-I I 22.
14. Waters KA, McBrien F, Stewart P, Hinder M, Wharton S: Effects of OSA, inhalational anesthesia, and fentanyl on the airway and ventilation of children. J Appl Physiol 2002, 92: I 987-1994.

15. Kerbl R, Zotter H, Schenkeli R, Hoffmann E, Perrogon A, Zotsch W, Kurz R: Persistent hypercapnia in children after treatment of obstructive sleep apnea syndrome by adenotonsillectomy. Wien Klin Wochenschr 200I, I I 3:229-234.

16. Ruboyianes JM, Cruz RM: Pediatric adenotonsillectomy for obstructive sleep apnea. Ear Nose Throat J 1996, 75:430-433.

17. Goodwin JL, Enright PL, Kaemingk KL, Rosen GM, Morgan WJ, Fregosi RF, Quan SF: Feasibility of using unattended polysomnography in children for research--report of the Tucson Children's Assessment of Sleep Apnea study (TuCASA). Sleep 200I, 24:937-944.

18. Rechtshaffen A, Kales A: A manual of standardized terminology: Techniques and scoring systems for sleep stages of human subjects. UCLA Brain Information Service/Brain Research Institute Los Angeles, CA; 1968.

19. Tang JP, Rosen CL, Larkin EK, DiFiore JM, Arnold JL, Surovec SA, Youngblut JM, Redline S: Identification of sleep-disordered breathing in children: variation with event definition. Sleep 2002, 25:72-79.

20. Fregosi RF, Seals DR: Hypoxic potentiation of the ventilatory response to dynamic forearm exercise. J Appl Physiol 1993, 74:2365-2372.

21. White DP, Douglas NJ, Pickett CK, Weil JV, Zwillich CW: Sexual influence on the control of breathing. J Appl Physiol 1983, 54:874-879.

22. American Thoracic Society: Standards and indications for cardiopulmonary sleep studies in children. Am J Respir Crit Care Med 1996, I 53:866-878.

23. American Thoracic Society: Cardiorespiratory sleep studies in children. Establishment of normative data and polysomnographic predictors of morbidity. Am J Respir Crit Care Med 1999, 160: I38I-I387.

24. Schechter MS: Technical report: diagnosis and management of childhood obstructive sleep apnea syndrome. Pediatrics 2002 , 109:e69.

25. Goodwin JL, Kaemingk KL, Fregosi RF, Rosen GM, Morgan WJ, Sherrill DL, Quan SF: Clinical Outcomes Associated with Sleep-Disordered Breathing in Caucasian and Hispanic Children-the Tucson Children's Assessment of Sleep Apnea Study (TuCASA). Sleep 2003, 26:587-91.

26. Carskadon MA, Harvey K, Dement WC, Guilleminault C, Simmons FB, Anders TF: Respiration during sleep in children. West J Med 1978, I 28:477-48|.

27. Gaultier C: Cardiorespiratory adaptation during sleep in infants and children. Pediatr Pulmonol 1995, 19:105-1 I7.

28. Schafer T: Variability of vigilance and ventilation: studies on the control of respiration during sleep. Respir Physiol 1998, I | 4:37-48.

29. Poets CF, Southall DP: Noninvasive monitoring of oxygenation in infants and children: practical considerations and areas of concern. Pediatrics 1994, 93:737-746.

30. Weitzenblum E, Hirth C, Parini JP, Roeslin N, Ravault MC, Oudet P: Comparative study of the ventilatory responsiveness to $\mathrm{CO} 2$ in bronchitic and emphysematous patients with chronic respiratory failure. Respiration 1976, 33:188-198.

31. Gozal D, Arens R, Omlin KJ, Ben-Ari JH, Aljadeff G, Harper RM, Keens TG: Ventilatory response to consecutive short hypercapnic challenges in children with obstructive sleep apnea.J Appl Physiol 1995, 79:1608-1614.

32. Berkenbosch A, Bovill JG, Dahan A, DeGoede J, Olievier IC: The ventilatory $\mathrm{CO} 2$ sensitivities from Read's rebreathing method and the steady-state method are not equal in man.J Physiol 1989, 4 I I:367-377.

33. Shi $Y X$, Seto-Poon M, Wheatley JR: The breathing route dependence of ventilatory responses to hypercapnia and exercise is modulated by upper airway resistance. Respirology 1999, 4:331-338.

34. Whitelaw WA, Derenne JP: Airway occlusion pressure. J Appl Physiol 1993, 74:1475-I483.

35. Radwan L, Koziorowski A, Maszczyk Z, Plywaczewski R, Boros P, Franczuk $M$, Kowalski J, Zielinski J: [Respiratory response to inspiratory resistive load changes in patients with obstructive sleep apnea syndrome]. Pneumonol Alergol Pol 2000, 68:44-56. 
36. Garcia-Rio F, Racionero MA, Pino JM, Martinez I, Ortuno F, Villasante C, Villamor J: Sleep apnea and hypertension. Chest 2000, II7:1417-1425.

37. Garcia-Rio F, Pino JM, Ramirez T, Alvaro D, Alonso A, Villasante C, Villamor J: Inspiratory neural drive response to hypoxia adequately estimates peripheral chemosensitivity in OSAHS patients. Eur Respir J 2002, 20:724-732.

38. Osanai S, Akiba Y, Fujiuchi S, Nakano H, Matsumoto H, Ohsaki Y, Kikuchi K: Depression of peripheral chemosensitivity by a dopaminergic mechanism in patients with obstructive sleep apnoea syndrome. Eur Respir J 1999, 13:418-423.

\section{Pre-publication history}

The pre-publication history for this paper can be accessed here:

http://www.biomedcentral.com/1471-2466/4/4/prepub

Publish with Bio Med Central and every scientist can read your work free of charge

"BioMed Central will be the most significant development for disseminating the results of biomedical research in our lifetime. "

Sir Paul Nurse, Cancer Research UK

Your research papers will be:

- available free of charge to the entire biomedical community

- peer reviewed and published immediately upon acceptance

- cited in PubMed and archived on PubMed Central

- yours - you keep the copyright 